\title{
On the Reduction of Transpiration Observations.
}

\author{
BY
}

NESTA THOMAS, B.Sc.,

Assistant Lecturer in Botany in the Royal Holloway College,

AND

ALLAN FERGUSON, M.A., D.Sc.,

Assistant Lecturer in Physics in the University College of North Wales, Bangor.

With one Figure in the Text.

Contents.

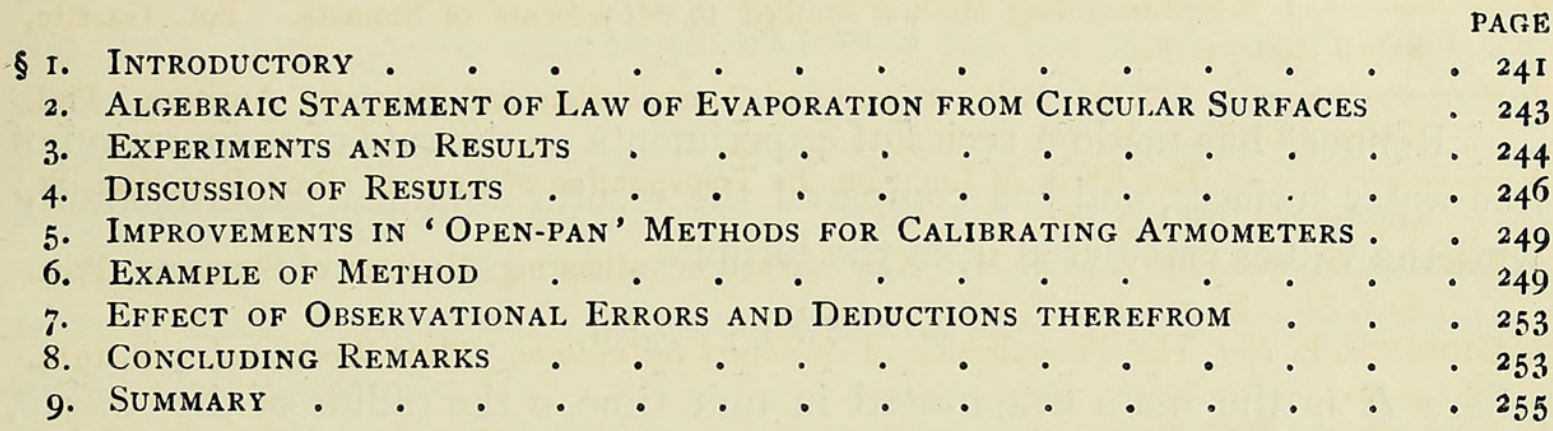

I. INTRODUCTORY.

I $\mathrm{N}$ the attempt to correlate plant transpiration with the purely physical process of evaporation various methods have been followed; in particular, the transpiration-loss may be compared with that suffered by a water surface (usually circular in shape) of known area, or, as is now more usually the case, with the loss, under similar conditions, of a porous atmometer of the type introduced by Livingston. But it is eminently desirable that the figures obtained by different investigators, under various conditions, should be capable of easy and accurate comparison; and since two atmometers, identical in size and shape, may differ so much in other qualities (e.g. in the porosity of the material of which they are constructed) as to render it impossible to compare the data given by them, some definite method of calibration has become necessary.

The plan adopted in the past and still used by some investigators is to compare the evaporation-loss from the atmometer with that from a circular

[Annals of Botany, Vol. XXXI. No. CXXII. April, r917.] 
water surface $; 1,2,3$ and, as the areas of the two evaporating surfaces are in general different, to reduce the observations by assuming that the evaporation from a free water surface is proportional to its area. This, except under certain special circumstances, is not even approximately true, and the present research was undertaken with the object of demonstrating the law actually followed, and of showing how the results obtained may be applied to place the figures acquired in transpiration experiments on a more consistent basis.

It has been demonstrated theoretically by $\operatorname{Stefan}^{4}$ that the rate of evaporation of a circular liquid surface evaporating into an indefinite homogeneous atmosphere is given by the equation

$$
V=4 k a \log _{e} \frac{P-p_{1}}{P-p_{0}}
$$

where $V$ is the volume evaporated in unit time, $\alpha$ the radius of the surface, $k$ the coefficient of diffusion, $p_{0}$ and $p_{1}$ the pressure of the vapour at the surface and at an infinite distance from it respectively, and $P$ the atmospheric pressure. If $p_{1}$ and $p_{0}$ be small with respect to $P$, this reduces to

$$
V=4 k a \frac{p_{0}-p_{1}}{P}
$$

Renner ${ }^{6}$ has made a series of experiments on the rate of evaporation of free water surfaces, and has compared the results obtained experimentally with the values calculated from the formula

$$
E=4 k\left(\rho_{1}-\rho_{2}\right) a,
$$

where $E$ is the mass evaporated in unit time, $a$ the radius of the surface, $k$ the coefficient of diffusion, $\rho_{1}$ the density of saturated vapour at the given temperature, $\rho_{2}$ the vapour density of the surrounding atmosphere at the same temperature. This formula is of a different form from that given by Stefan, and it is to be remembered that, granted the proper conditions, Stefan's formula provides an exact solution. Renner compares the experimental results with those calculated from three formulae, viz. $C_{4} R, C_{4} \pi R$, and $C \pi R^{2}$, where $C \equiv k\left(\rho_{1}-\rho_{2}\right)$ 6o.

${ }^{1}$ Cf. Livingston: The Relation of Desert Plants to Soil Moisture and Evaporation. Carnegie Inst. Publications, No. 50, 1906.

2 Shreve: The Daily March of Transpiration in a Desert Perennial. Carnegie Inst. Publications, No. 194, 1914.

3 Yapp: On Calibration of Evaporimeters. Appendix to paper On Stratification in the Vegetation of a Marsh, and its Relations to Evaporation and Temperature. Ann. Bot., I909.

4 Stefan: Ueber die Verdampfung aus einem kreisförmig oder elliptisch begrenzten Becken. Wied. Ann., xvii, I882, p. $55^{\circ}$.

5 This equation is misquoted by Brown and Escombe as $4 k a \frac{P-p_{1}}{P-p_{0}}$. Phil. Trans., B., vol. cxciii, I900, p. 25 I.

6 Renner : Beiträge zur Physik der Transpiration. Flora, 1900, p. $4^{8} 5$ et seq. 
An examination of his tabulated results shows that such agreement as exists is purely fortuitous-for some values of $a$ one formula shows fair agreement, for other values the other formulae are invoked. The figures show that the agreement, for example, of the values calculated from $C \pi R^{2}$ does not necessarily represent any physical fact, but is simply an expression of the mathematical fact that two quite unrelated curves may approximately coincide for a small portion of their length.

The figures obtained from the formula expressing the linear law and those obtained from the formula expressing the area law may be so different that the errors introduced by reduction according to the erroneous formula may be large enough to rob the results of any meaning.

Thus, in the laboratory experiment to determine the relation between the amount of evaporation per unit time from a leaf surface and from a water surface of equal area, Detmer ${ }^{1}$ gives the figures for an actual experiment which yields the result

$$
\frac{\text { Water lost by } 100 \text { sq. } \mathrm{cm} \text {. of water surface }}{\text { Water lost by } I 00 \mathrm{sq} . \mathrm{cm} \text {. of leaf surface }}=\frac{\mathrm{II} \cdot 3}{\mathrm{I} \cdot 99}=5 \cdot 68 \text {. }
$$

This result was obtained by reducing the experimental figures according to the 'area' law. If we assume Stefan's law for the evaporation from the water surface, and assume further (as Detmer does) that the evaporation from the leaf surface is proportional to its area, the above ratio becomes 2.53-an error of about I 20 per cent.! It is not too much to assert that, until reasonable certainty exists as to the true law connecting the evaporation from a water surface with its area, such figures possess no quantitative significance whatever.

Certain deductions from Stefan's law have been subjected to the test of experiment by Winkelmann ${ }^{2}$ and by v. Pallich. ${ }^{3}$ Apart from the closely analogous experiments on diffusion carried out by Brown and Escombe ${ }^{4}$ and more recently by Renner, ${ }^{5}$ we are not acquainted with, however, any results which give the laws connecting $E$ and $a$ under various 'everyday' conditions ; and the experiments detailed below are offered as a contribution towards the establishment of such laws.

\section{Algebraic Statement of Law of Evaporation from Circular Surfaces.}

We assume then that the law of evaporation from a circular basin of water or other liquid is given by an equation of the type

$$
E=K a^{n} \ldots(\mathrm{i}) \text {, }
$$

1 Detmer : Practical Plant Physiology. (Eng. Translation by Moor, 1909, p. 21 2.)

2 Winkelmann: Ueber die Verdampfung von den einzelnen Theilen einer kreisförmigen freien Oberfläche. Wied. Ann., xxxv, I888, p. 4 ㅇ․

3 J. v. Pallich : Über Verdunstung aus einem offenen kreisförmigen Becken. Berlin. Akad., Sitz., I06, p. 384, I897, and Sci. Abs., i, p. 203, I898.

4 Loc. cit., p. 223. 
where $E$ is the evaporation per unit time, and $a$ the radius of the basin-or rather, of the evaporating water surface. $K$ and $n$ are constants, and it is our object to determine the values of $K$, and especially of $n$, under various external conditions. Having measured $E$ and $a$ experimentally, we obtain by taking logarithms of equation (i)

$$
\log E=\log K+n \log a \ldots \text { (ii), }
$$

and on plotting $\log E$ against $\log a$ we should obtain a straight line. The tangent of the angle which this straight line makes with the $x$-axis at once gives $n$, whilst $\log K$-and therefore $K$-is given by the magnitude of the intercept made by the straight line on the $y$-axis. Thus $n$ and $K$ are easily and accurately obtained from the graph. They may, of course, also be obtained by treating the experimental data by the method of least squares, if the observations admit of such treatment.

If we then find that $n=\mathrm{I}$, this constitutes a verification of the law propounded by Stefan; if $n=2$, the 'area ' law is justified ; and in any case, independently of any theoretical assumption, the value of $n$ appropriate to the given external conditions can be obtained without any uncertainty.

This method of procedure appears to us to possess some advantages over those usually employed. In the classic paper of Brown and Escombe, for example, the method of reduction of the results merely shows that the experimental data are better suited by the linear than by the area law. If the logarithms of one set of their data ${ }^{1}$ be plotted out in the manner explained above, and a straight line be drawn through the mean position of the points so plotted, it will be seen that the value of $n$ which best fits their data is not $I$, but 0.87 (approximately). The points are somewhat irregularly placed, but this is a natural consequence of the extreme difficulty of the experiments, and of the necessary smallness of the apertures employed.

\section{Experiments and Results.}

In the experiments now to be described, a series of fourteen cylindrical crystallizing dishes, whose radii varied from 2 to Io centimetres, was employed, each of the dishes being filled to a definite distance $(d)$ from the upper rim ; after weighing the dishes, the whole series was set out on a table, each dish being separated from its nearest neighbours by a distance which was several times greater than its own diameter; weighings were then made after the lapse of a definite time and the mean evaporation per hour $(E)$ was thus obtained. Readings of the barometer were taken at the beginning and end of a run, and observations of the relative humidity of the air were made by means of a Regnault hygrometer. A maximum and minimum thermo- 
meter served to show the extreme range of the temperate changes during the progress of an experiment.

Observations were taken in three different localities: (I) in a 'dark' room with blackened walls, having a floor space of about 400 square feet: this room was chosen for its steady temperature properties, as the only portion of its walls which abutted on the external air was that occupied by a moderately large window; (2) in a large room used as a general laboratory, well lighted from above, and with a floor space of about 600 square feet; and $(3)$ in the open air.

It is not necessary to give full details of all the figures obtained in the various experiments. One set of such figures may, however, be of interest as showing both the accuracy obtainable and the magnitude of the various quantities involved. They are the result of an experiment made under 'dark' room conditions with the levels of the evaporating surfaces at the beginning of the experiment $0.7 \mathrm{~cm}$. below the rims of the respective vessels, ${ }^{1}$ and are given in Table I below.

\section{TABLE I.}

Mean height of barometer $=29^{\prime \prime} \cdot 6$ (steady)

Max. temp. $=18^{\circ} \cdot 8 \mathrm{C}$. Min. temp. $=17^{\circ} \cdot 7 \mathrm{C}$.

Relative humidity $=63$ per cent.

$$
d=0.7 \mathrm{~cm} . \quad \quad k=0.010 \mathrm{I} . \quad n=\mathrm{I} .69 \text {. }
$$

\begin{tabular}{|c|c|c|c|c|c|c|c|c|}
\hline a. & $\log a$ & \multicolumn{2}{|c|}{ Time. } & $\begin{array}{l}\text { Loss in } \\
\text { weight. }\end{array}$ & $\begin{array}{c}\log E \\
(o b s d .) .\end{array}$ & $\begin{array}{c}E \\
\text { (obsd.). }\end{array}$ & $\begin{array}{c}E \\
\text { (cald.). }\end{array}$ & $\%$ error. \\
\hline $\mathrm{cm}$. & & h. & $\mathrm{m}$. & grm. & & & & \\
\hline 10.17 & $1 \cdot 0073$ & 43 & 4 & 22.10 & $\overline{\mathbf{I}} \cdot 7103$ & 0.5133 & $0.506_{4}$ & $-I \cdot 34$ \\
\hline $8 \cdot 26$ & 0.9170 & 43 & o & I $5 \cdot$ I 5 & $\overline{\mathbf{I}} \cdot 5470$ & $0.35^{2} 4$ & 0.3579 & $+1 \cdot 56$ \\
\hline $7 \cdot 03$ & 0.8470 & $4^{2}$ & $5^{8}$ & 11.90 & $\overline{1} \cdot 44^{24}$ & 0.2770 & 0.2727 & $-\mathrm{I} \cdot 55$ \\
\hline $5 \cdot 84$ & 0.7664 & $4^{2}$ & 54 & 8.60 & $\overline{1} \cdot 3021$ & 0.2004 & 0.1989 & -0.75 \\
\hline 5.00 & 0.6990 & $4^{2}$ & 53 & $6 \cdot 45$ & $\overline{\mathrm{I}} \cdot \mathrm{I} 774$ & 0.1504 & 0.1530 & $+\mathrm{I} \cdot 73$ \\
\hline $4 \cdot 3^{8}$ & 0.64 I 5 & $4^{2}$ & 54 & $5 \cdot 25$ & $\overline{\mathbf{I}} \cdot 0878$ & 0.1224 & 0.1224 & \pm 0.00 \\
\hline $3^{\circ} 91$ & 0.5922 & 42 & $5^{8}$ & 4.373 & $\overline{2} \cdot 9977$ & 0.0995 & O.IOII & $+1 \cdot 6 I$ \\
\hline $3 \cdot 30$ & 0.5185 & $4^{2}$ & 59 & $3 \cdot 286$ & $\overline{2} .8835$ & 0.0765 & $0.075^{8}$ & $-0.9 I$ \\
\hline $2 \cdot 84$ & 0.4533 & $4^{2}$ & 59 & $2 \cdot 422$ & $\overline{2} .7510$ & 0.0564 & 0.0589 & $+4 \cdot 43$ \\
\hline 2.08 & $0.3 I 8 I$ & $4^{2}$ & $5^{8}$ & $I \cdot 484$ & $\overline{2} \cdot 53^{84}$ & 0.0345 & $0.034^{8}$ & +0.87 \\
\hline
\end{tabular}

Average error regardless of sign $=1.47$ per cent.

In the above table, the first column gives the radii of the dishes used, the sixth column gives the rate of evaporation from each basin in grammes per hour as deduced from the data given in the preceding columns, whilst the seventh column gives the values of $E$ as calculated from the equation

$$
E=0.0101 a^{1.69} \text {. }
$$

The constants in this equation were obtained, as explained above, by plotting the observed values of $\log E$ and $\log a$ against each other. It will be seen

${ }^{1}$ At the end of the experiment the values of $d$, calculated from the known values of the evaporation and the radii, in the above table were increased to $0.77,0.77,0.78,0.78,0.78$, $0.79,0.79,0.80,0.80,0.8 \mathrm{I} \mathrm{cm}$. respectively. 
that the observed and calculated values of $E$ are in satisfactory agreement, the percentage error being shown in the last column.

It is not necessary to give full details of any of the other experiments made. A number of the graphs of $\log E$ and $\log a$ are given in Fig. I below, and it will be seen that in all cases the graphs are fairly accurately linear, whilst the variation of $n$ under different circumstances is clearly shown by the varying slope of the different lines.

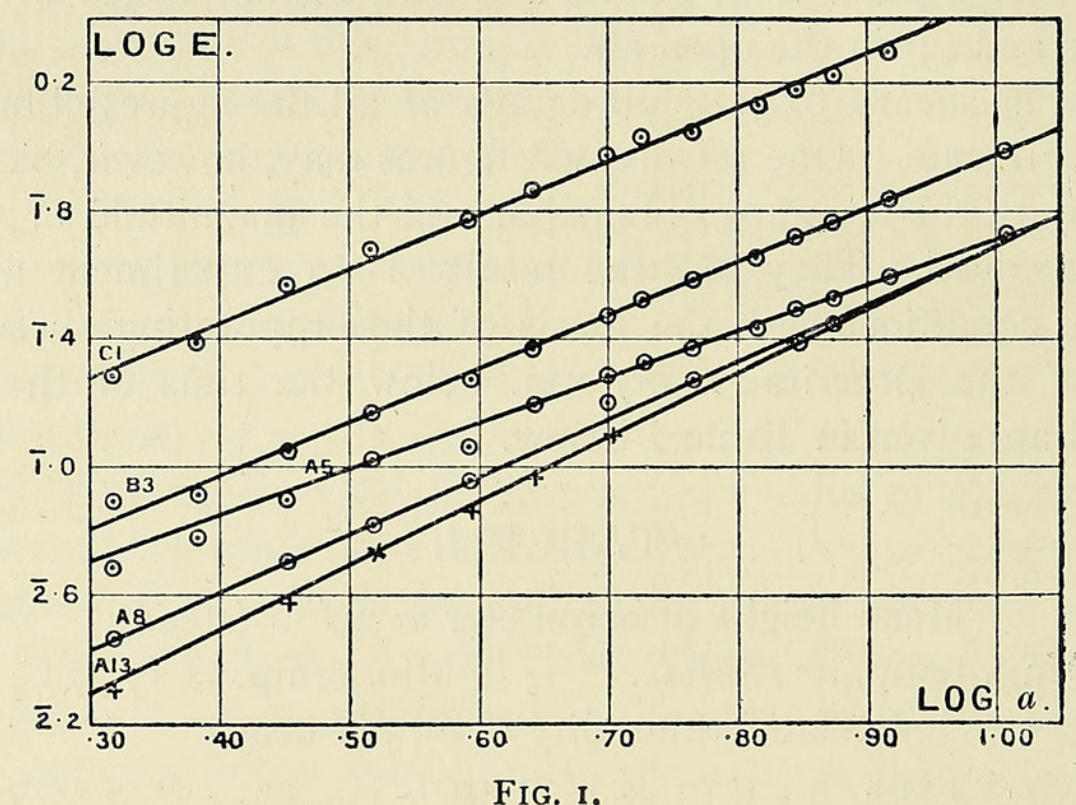

The letters appended to the various lines in Fig. I are identical with those in the first column of Table II. A reference to this table will therefore show at once the conditions under which the experiment was made.

In Table II below we have a synoptic view of the results of the whole series of experiments. Those indexed A were carried out under 'dark' room conditions; experiments under the index $\mathrm{B}$ were made in a room typical of an ordinary laboratory, and those under the index $\mathrm{C}$ were made in the open air. The seventh column gives the distance $d$ of the level of the evaporating water surface below the rim of the containing vessel, while the eighth and ninth columns give the values of $k$ and of $n$ in

$$
E=k a^{n}
$$

as deduced from the graphs of the logarithms of the observed values of $E$ and of $a$. (It should be noted that in experiments A 3 and $\mathrm{A}_{4}$ a maximum and minimum thermometer was not used, and the mean temperatures given are the means of several readings of an ordinary thermometer.)

\section{Discussion of Results.}

The preceding table brings out several points of primary importance in connexion with the main problem under discussion-the calibration of atmometers. In the first place it is to be noted that under no circumstances 
TABLE II.

\begin{tabular}{|c|c|c|c|c|c|c|c|c|}
\hline & Barometer & Ten & atures & ${ }^{\circ} \mathrm{C}$. & Rel. Hum. & $d$. & $k$. & $n$. \\
\hline & (Mean). & Max. & Min. & Mean. & (Mean). & $\left(\mathrm{cm} \mathrm{m}_{0}\right)$. & & \\
\hline A I & $\begin{array}{c}\text { inches. } \\
30^{\circ} 19\end{array}$ & I5.I & 14.7 & I $4^{\circ} 9^{I}$ & $56 \%$ & 0.0 & $0.030 ?$ & $1 \cdot 43$ \\
\hline A 2 & 30.14 & $15 \cdot 7$ & $15^{\circ} 0$ & 14.35 & 73 & 0.3 & 0.0126 & 1.60 \\
\hline$A_{3}$ & $30 \cdot 20$ & $\ldots$ & $\ldots$ & 19.55 & 73 & 0.5 & 0.0187 & $I \cdot 49$ \\
\hline$A_{4}$ & $30 \cdot 78$ & $\ldots$ & $\ldots$ & 10.85 & & 0.5 & 0.0168 & $1 \cdot 50$ \\
\hline A 5 & $30 \cdot 89$ & $22 \cdot 5$ & $18 \cdot 7$ & $20 \cdot 60$ & 69 & 0.5 & 0.0158 & $I \cdot 46$ \\
\hline 16 & $29^{\circ} 94$ & $16 \cdot \mathrm{I}$ & $15 \cdot 3$ & $15 \cdot 70$ & 74 & 0.5 & 0.0109 & $1 \cdot 62$ \\
\hline 7 & 29.60 & $18 \cdot 8$ & $17 \cdot 7$ & $18 \cdot 25$ & 70 & 0.7 & 0.0101 & $1 \cdot 69$ \\
\hline 8 & $29 \cdot 77$ & $18 \cdot 4$ & $17 \cdot 8$ & $18 \cdot 10$ & 73 & $1 \cdot 0$ & 0.0079 & $1 \cdot 78$ \\
\hline 9 & 29.60 & $18 \cdot 8$ & $17 \cdot 7$ & $18 \cdot 25$ & 70 & $1 \cdot 2$ & 0.0063 & $I \cdot 86$ \\
\hline 10 & $29 \cdot 49$ & $18 \cdot 8$ & I $8 \cdot \mathrm{I}$ & 18.45 & 76 & $1 \cdot 5$ & 0.0053 & $I \cdot 82$ \\
\hline II & $30 \cdot 13$ & $15 \cdot 7$ & $15^{\circ} \mathrm{O}$ & I 5.35 & 73 & 1.5 & 0.0048 & $\mathrm{I} \bullet 88$ \\
\hline I 2 & 29.95 & 18.7 & $17 \%$ & 18.05 & 67 & $2 \cdot 0$ & 0.0053 & I.99 \\
\hline 13 & 29.69 & $19 \cdot 8$ & $18 \cdot 7$ & 19.25 & 72 & $2 \cdot 5$ & 0.0050 & I.99 \\
\hline 414 & 29.57 & $20 \cdot 3$ & $19 \cdot 2$ & 19.75 & iI & $2 \cdot 5$ & 0.0056 & I. 97 \\
\hline$A_{15}$ & 29.83 & $19^{\circ} 0$ & $18 \cdot 5$ & $18 \cdot 75$ & $7 \mathrm{I}$ & $3 \cdot 0$ & 0.0049 & I.97 \\
\hline & $30 \cdot 24$ & $21 \cdot 7$ & $17 \cdot 7$ & 19.70 & 6 & 0.5 & 0.0291 & $\mathrm{I} \cdot 5^{8}$ \\
\hline & 30.23 & $21 \cdot 7$ & $18 \cdot \mathrm{I}$ & 19.90 & 60 & 0.6 & 0.0268 & 1.57 \\
\hline 33 & $30 \cdot 2 \mathrm{I}$ & $21 \cdot 3$ & $18 \cdot 3$ & 19.80 & 66 & 0.7 & 0.0206 & $1 \cdot 65$ \\
\hline 34 & 29.55 & $16 \cdot 8$ & $14 \cdot 7$ & I $5 \cdot 76$ & $9^{\circ}$ & $2 \cdot 5$ & 0.0031 & 2.00 \\
\hline & $29.6 \mathrm{I}$ & $I 7 \cdot I$ & $13 \cdot 9$ & $155^{\circ}$ & 84 & $2 \cdot 5$ & 0.0047 & $I \cdot 98$ \\
\hline & $30 \cdot 2 \mathrm{I}$ & $21 \cdot 8$ & I $8 \cdot 9$ & 0.35 & 68 & 0.5 & 0.0607 & $1 \cdot 67$ \\
\hline & $29^{\circ} 95$ & 15.7 & 14.7 & $15.2 \mathrm{I}$ & 78 & $2 \cdot 7$ & 0.0379 & I. \\
\hline & & $2 \cdot 4$ & $I \cdot 4$ & $I \cdot 9$ & 66 & $3 \cdot 0$ & 0.0007 & \\
\hline
\end{tabular}

does the magnitude of $n$ fall to unity - the value demanded by Stefan's law. The probable reasons for this do not here concern us-these, and several other points of purely physical interest, we hope to be able to publish later through the proper channels. It is sufficient here to note the fact itself.

Again, as the depth of the liquid surface below the rim increases, $n$ also increases, rapidly at first, and then more slowly, until when $d$ is greater than about 3 centimetres, $n$ has become practically equal to 2 , and the 'area' law holds good.

Thirdly, if the depth remain constant, and the external circumstances are varied in the direction of a greater disturbance of the atmosphere, $n$ also increases, but only relatively slowly. The experiment $\mathrm{C}$ I, for example, was carried out in the open air, with a gentle breeze blowing sufficiently hard to ruffle continually the liquid surfaces exposed. Even under these conditions the value of $n$ was no greater than $1 \cdot 67$. We found this result somewhat surprising, as we had expected, from a priori considerations, that the large disturbance induced in the lines of flow by a steady breeze would tend to make $n$ practically equal to 2. This is, however, by no means the case, as indeed Stefan has indicated. ${ }^{1}$

We may say then that, under all ordinary circumstances, the value of $n$, for a vessel filled to within 5 millimetres of the brim, varies from I.5 to I.7 
(approximately $\mathrm{I} \cdot 6$ ), and that for a vessel filled to about 3 centimetres from the brim, under similar circumstances, the value of $n$ is practically equal to 2.

Unfortunately the importance of filling the calibration vessel to a definite distance from the rim has not, so far as we are aware, received due recognition. The vessel is usually spoken of as being 'filled' with water ; and, where any quantitative details are given, this appears to mean 'filled to within 5 or 6 millimetres of the brim'. 1 Darwin and Acton, indeed, in discussing a very similar problem, recommend the use of a 'shallow vessel ' $;{ }^{2}$ as their results, however, are to be reduced by the area law, it is the very opposite that is required-a deep vessel, filled to about 3 centimetres from the brim. Otherwise, the calculated results cannot have any quantitative meaning.

The serious difference that may exist between the true value of $n$ and that usually assigned to it may, as we shall show, introduce errors in the calculated value of the equivalent water surface of an atmometer that may be as great as 30 or 40 per cent. This being so, it is hardly too much to say that any figures obtained from two different atmometers, and any figuressuch as those of 'relative transpiration'-based on readings of atmometers calibrated by comparison with water surfaces assuming the area law, cannot by any means be compared one with another. Not only are the numerical magnitudes of the figures involved probably in error, but the degree of the error, depending as it does on the true value of $n$, is also variable, and is variable by an amount that cannot be estimated so long as the exact conditions of the experiment remain unspecified.

It is evident then, that to remove this unfortunate uncertainty, it is necessary to calibrate an atmometer by means of some quantity that shall possess those qualities which are usually demanded of a standard or unitthat is, it must be constant under constant and easily specified conditions, and must be capable of reproduction at any place or time. The figures cited above seem to show that a free water surface contained in a cylindrical basin fulfils these conditions. The surface is one which can easily be reproduced and the evaporation from such a surface follows a regular law. Further, the value of the constants in

$$
E=k a^{n}
$$

can readily be calculated. Secondly, after the depth of the free surface of the water below the rim of the containing vessel has reached a certain value, evaporation is proportional to the area, and therefore a water surface of this kind may, without further difficulty, be used for standardizing purposes.

1 Yapp filled the crystallizing dish used to calibrate his atmometers to 'about $3 \mathrm{~mm}$. below its upper edge'. Loc. cit., p. 3 II.

2 Darwin and Acton: Practical Physiology of Plants, I894, p. 89. 


\section{Improvements in 'Open-Pan' Methods for CAlibrating ATMOMETERS.}

It appears to us that if a water surface be used as standard, two methods of procedure may be followed:

(I) In calibrating the atmometer, three or more basins of varying radii may be used, filled to about 5 millimetres from the rim. The actual value of $n$ may then be determined by plotting $\log E$ against $\log a$, as previously explained. Then if $E$ be the evaporation per unit time from the basin of radius $a_{1}, E_{2}$ the evaporation per unit time from the evaporimeter, and $a_{2}$ the radius of its equivalent surface

or

$$
\frac{E_{1}}{E_{2}}=\left(\frac{a_{1}}{a_{2}}\right)^{n},
$$

$$
\log a_{2}=\frac{n \log a_{1}-\log E_{1}+\log E_{2}}{n}
$$

giving $a_{2}$. The area $(A)$ of the equivalent water surface is then given by

$$
A=\pi a_{2}{ }^{2} \text {. }
$$

(2) In the second method, although a single basin is sufficient, two or three basins may preferably be employed to minimize incidental errors. Each basin should be filled to a depth of about 3 centimetres from the rim, when it can safely be assumed that $n=2$. Then, using the same notation as before, we have

or

$$
\frac{E_{1}}{E_{2}}=\frac{\pi a_{1}^{2}}{A},
$$

$$
A=\frac{\pi a_{1}^{2} E_{2}}{E_{1}} .
$$

The equivalent area $A$ should be calculated from each of the basins employed, and the mean taken.

This appears to be the method to be preferred. Such a water surface seems to possess the qualities of constancy and of easy reproduction which are absolutely necessary in every practical standard, and its general use would, we think, remove the great uncertainty which is an undesirable feature of the present methods of calibration. Moreover, as will shortly be shown, a consideration of the relative errors in the different quantities involved will enable us to remove practically every source of uncertainty and to make the calibration as accurate as the circumstances may demand.

\section{Example of Method.}

Meantime, a practical example will perhaps help to make matters clear :

The transpiration from a small Pelargonium was determined in the usual manner, taking all ordinary precautions. In order to determine the 
equivalent area of the transpiring surface of the plant two sets of calibrating vessels, three in each set, were employed. In one set (vessels $C, E$, and $G$ ) the dishes were filled to 5 millimetres from the rim, in the second set $(D, F$, and I) to 3 centimetres. The following figures were obtained :

\section{TABLE III.}

\begin{tabular}{|c|c|c|c|c|}
\hline & Radius. & $\begin{array}{l}\text { Loss in } \\
\text { weight. }\end{array}$ & $\begin{array}{l}\text { Dura } \\
\text { exper }\end{array}$ & $\begin{array}{l}\text { ion of } \\
\text { ment. }\end{array}$ \\
\hline Plant & $\ldots$ & $6 \cdot 45$ grammes. & $\begin{array}{l}\text { h. } \\
68\end{array}$ & $\begin{array}{l}\mathrm{m} . \\
\mathrm{I} 2\end{array}$ \\
\hline $\begin{array}{l}\text { C. } \\
\text { E. } \\
\text { G. }\end{array}$ & $\begin{array}{l}8 \cdot 26 \mathrm{~cm} . \\
7 \cdot 03 \\
5 \cdot 84\end{array}$ & $\begin{array}{l}29 \cdot 55 \\
23.38 \\
16.55\end{array}$ & $\begin{array}{l}68 \\
68 \\
68\end{array}$ & $\begin{array}{r}23 \\
26 \\
2\end{array}$ \\
\hline $\begin{array}{l}\text { D. } \\
\text { F. } \\
\text { I. }\end{array}$ & $\begin{array}{l}7 \cdot 48 \\
6 \cdot 45 \\
5 \cdot 00\end{array}$ & $\begin{array}{r}16 \cdot 80 \\
12 \cdot 15 \\
7.5 \mathrm{I}\end{array}$ & $\begin{array}{l}68 \\
68 \\
68\end{array}$ & $\begin{array}{r}10 \\
10 \\
6\end{array}$ \\
\hline
\end{tabular}

The mean rate of evaporation of the plant is therefore 0.0946 gramme per hour. If we assume, as we have shown to be justifiable, the area law for $\mathrm{D}$, $\mathrm{F}$, and $\mathrm{I}$, we obtain, in determining the equivalent water surface $(A)$ of the plant by means of the equation

(a) from $\mathrm{D}, A=67.45$ sq. cm.,

$$
A=\frac{\pi a_{1}^{2} E_{2}}{E_{1}}
$$

( $\beta$ ) from $\mathrm{F}, A=69.34$ sq. cm.,

$(\gamma)$ from I, $A=67 \cdot 48$ sq. cm.,

giving a mean value of $68.09 \mathrm{sq} . \mathrm{cm}$. for $A$.

In reducing the data obtained from $\mathrm{C}, \mathrm{E}$, and $\mathrm{G}, \log E$ was plotted against $\log a$ in the usual way, and the resulting straight line showed that the appropriate value of $n$ was I.58. Hence using the equation

we obtain,

$$
\log a_{2}=\frac{n \log a_{1}-\log E_{1}+\log E_{2}}{n}
$$

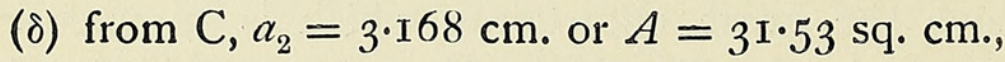

(є) from E, $a_{2}=3.126 \mathrm{~cm}$. or $A=30.70 \mathrm{sq} . \mathrm{cm}$.,

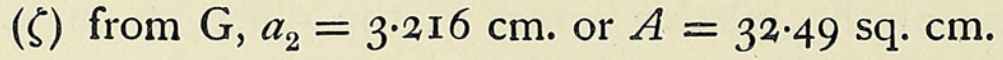

The mean value of $A$ is therefore $3 \mathrm{I} \cdot 57$ sq. $\mathrm{cm}$.

Hence we see that the plant loses water at the same rate as a circular water surface $3^{\mathrm{I}} \cdot 6$ square centimetres in area filled to a distance of 5 millimetres from the rim of the containing vessel; or at the same rate as a circular water surface 68. I square centimetres in area filled to a distance of 3 centimetres from the rim. The vital importance of specifying this distance is here shown to be very obvious. 
It is equally important that the true value of $n$ should be used in reducing the observations. Suppose, for example, that in the case last discussed we reduce the observations, assuming, as is ordinarily done, the area law. We should then obtain

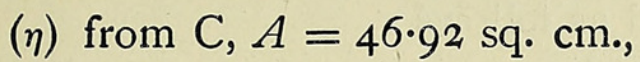

( $\theta)$ from $\mathrm{E}, A=42.98$ sq. cm.,

(๖) from $\mathrm{G}, A=4 \mathrm{I} \cdot 66 \mathrm{sq}$. cm.,

giving as a mean value $A=43.85 \mathrm{sq} . \mathrm{cm}$. Now, other considerations apart, the steady decrease in the value of $A$ with decrease in the radii of the calibration vessels is sufficient to indicate that something is probably wrong ; but, as we have seen, the true value of $A$ is $3 \mathrm{I} \cdot 6$ sq. $\mathrm{cm}$., and therefore the calculation of $A$ by the usual method introduces an error into the equivalent area of no less than 39 per cent.! This experiment-for, of course, the plant simply serves the purpose of a model atmometer-seems to us to demonstrate beyond reasonable doubt that the method of calibrating an evaporimeter by assuming the area law for a circular basin filled to within a small distance of the rim introduces such errors as to make it quite impossible to compare the results of different instruments; and it seems to be equally true that the figures usually given to show the ratio between the transpiration per square centimetre from a leaf surface and the evaporation per square centimetre from a circular water surface are quite void of any quantitative significance.

As an example of the errors introduced, the figures given by Yapp, who reduces his observations according to the 'area' law, may be taken. ${ }^{1}$ His method of procedure, which is given arithmetically, differs slightly from the manner of reduction discussed in this paper, but the underlying principles are identical. Reduced to symbols the argument may be stated thus:

Let $E_{a}$ be the rate of evaporation from the atmometer, $A_{a}$ the area of its equivalent water surface. Let $E_{d}$ be the evaporation from the standardizing dish, $A_{d}$ its area.

Then it is assumed that

or

$$
\frac{E_{a}}{E_{d}}=\frac{A_{a}}{A_{d}}
$$

$$
\begin{aligned}
A_{a} & =A_{d} \times \frac{E_{a}}{E_{d}}=62.07 \times \frac{50.40}{15.51} \\
& =62.07 \times 3.25,
\end{aligned}
$$

using the figures for Yapp's $1908 \mathrm{I}$ atmometer. This atmometer had a superficial area of $14 I^{\circ} 2 \mathrm{sq}, \mathrm{cm}$, and hence we find that the ratio of the area of the atmometer to that of the water surface which evaporates at an equal rate is

$$
\begin{aligned}
& \frac{\mathrm{I} 4 \mathrm{I} \cdot 2}{62 \cdot 07 \times 3.25}=\frac{\mathrm{I}}{\mathrm{I} \cdot 43}, \\
& { }^{1} \text { Loc. cit., p. 3I I seqq. }
\end{aligned}
$$


or, a square centimetre of atmometer surface evaporates $\mathrm{I} \cdot 43$ times as fast as a square centimetre of free water surface.

Evaporation results are often given by ecologists and meteorologists in linear measure. The method of reduction is illustrated by Yapp in his paper, ${ }^{1}$ and the argument may be stated as follows :

Let the rate of evaporation from the atmometer be $x$ c.c. per unit time. Then taking the figures given by Yapp's 1908 I atmometer, the circular water surface from which this would evaporate in the same time must have an area of $62.07 \times 3.25$ (or $14 \mathrm{I} \cdot 2 \times \mathrm{I} \cdot 43$ ) sq. $\mathrm{cm}$. If $d$ be the depth evaporated, then since the volume of a cylinder $=A \times d$

or

$$
\begin{aligned}
& \mathrm{I} 4 \mathrm{I} \cdot 2 \times \mathrm{I} \cdot 43 \times d=x, \\
& d=\frac{x}{\mathrm{I} 4 \mathrm{I} \cdot 2 \times \mathrm{I} \cdot 43}=\frac{x}{202},
\end{aligned}
$$

which is the figure given by Yapp.

But this result again is based on the assumption that the 'area' law of evaporation is the true one. Let us attempt to find the law of reduction from cubic to linear measure, making no assumptions as to the law of evaporation. If $E$ be the mass of water evaporated per unit time from a circular basin of radius $r$, then

$$
E=k r^{n} \text {. }
$$

But if $d$ be the depth evaporated

$$
E=\pi r^{2} d \rho
$$

where $\rho$ is the density of water. Hence

$$
d=\frac{k}{\pi \rho} \frac{r^{n}}{r^{2}}=K \frac{r^{n}}{r^{2}}
$$

where $K$ is a constant. If $n=2$ - the usual assumption-then $d=K$, and under these circumstances, and only under these circumstances, will the evaporation in linear measure be independent of the radius of the basin employed.

The calibrating dish used by Yapp was filled to about $3 \mathrm{~mm}$. below its upper edge. Under these conditions the appropriate value of $n$ is approximately $1 \cdot 5$. Whence we have

$$
d=K \frac{r^{1.5}}{r^{2}}=\frac{K}{\sqrt{r}}
$$

that is, the evaporation in linear measure from a circular water surface is inversely as the square root of its radius. As an illustration, if we had two such dishes, one four times the radius of the other, the depth evaporated in unit time from the larger basin would only be one-half of that evaporated in the same time from the smaller basin. The possibility of the existence of

${ }^{1}$ Loc. cit , p. $3^{1} 5$. 
discrepancies of this magnitude forces us to the conclusion that very little reliance can be placed on figures for evaporation in linear measure obtained on the assumption of the area law.

\section{EFFEct of ObServational ERrors and Deductions THEREFROM.}

It remains now to discuss the effect of given errors in the observed quantities on the resulting errors in the computed quantities. The point of most importance so far as we are concerned is the relation between the percentage error introduced into the value of the radius (or area) of the equivalent water surface of an atmometer by a given percentage error in the determination of $n$.

Let $E_{1}$ and $E_{2}$ represent the evaporation per unit time from the atmometer and calibrating dish respectively; let $r_{2}$ represent the radius of this latter vessel, and $r$ that of the surface equivalent to the atmometer. Then

$$
\frac{E_{1}}{E_{2}}=\left(\frac{r}{r_{2}}\right)^{n}
$$

and, remembering that $E_{1}, E_{2}$, and $r_{2}$ are given constants, we obtain at once by differentiating logarithmically

$$
\frac{\delta r}{r}=\frac{\delta n}{n} \log _{e} \frac{r_{2}}{r}
$$

This result shows, as is otherwise obvious, that, when the radius of the calibrating dish is very nearly equal to the equivalent radius of the atmometer, a large percentage error in $n$ may have very little effect in producing errors in $r$, and it may be very usefully and easily applied further to reduce any uncertainty that may exist as to the true value of the equivalent radius.

The procedure, then, that appears to us to be safest to follow in calibrating an atmometer is-first perform the calibration with two or three vessels filled to about 3 centimetres from the brim; reduce the observations, assuming the area law, for each basin separately, and thus obtain a mean value for the equivalent area, in the manner previously demonstrated. This value may be slightly in error, owing to a slight error in the assumed value of $\mathrm{n}$; but if we now repeat the experiment, using as a calibrating vessel a dish whose area is as near to this mean value as is conveniently possible, the value of the equivalent area deduced from this last experiment will be accurate enough for all practical purposes.

\section{CONCLUding REMARKS.}

During the course of his experiments on atmometry, Livingston first used, then discarded, the method of calibration by comparison with free water surfaces $;^{1,2}$ and in the experiments carried out during the year 1912

1 Livingston (1906), loc. cit.

2 Ibid.: Operation of the Porous Cup Atmometer. Plant World, I3, I910. 
and subsequently he has calibrated the instruments by comparison with a standard atmometer. ${ }^{1,2}$ If comparable results are desired by investigators in widely separated laboratories, this entails the possession of secondary standards which have been calibrated by comparison with the standard atmometer-a condition which is evidently inconvenient and far from ideal. Especially when one is aiming at an accuracy of one or one-half of one per cent., it seems preferable to attempt to realize a standard which shall be, as we have already pointed out, invariable under given conditions and capable of easy reproduction at any place or time. The free surface of water contained in a cylindrical vessel and protected by a rim of $3 \mathrm{~cm}$. depth fulfils these conditions. Moreover, the use of a free water surface for purposes of calibration avoids the assumption that the porous properties of the porcelain of the standard atmometers remain unchanged with time.

It may be that other factors-such as convection-may still introduce such errors as to preclude the use of the open pan as a standard. But we think that these sources of error have been somewhat too hurriedly invoked to explain observational discrepancies, while the greater sinner- $n-$ has been allowed to pass unrebuked.

We do not think that the errors introduced by convection are likely to be as large as is commonly assumed; were this the case, the logarithmic curves obtained for a series of basins of widely differing radii, tested under all sorts of external conditions, would not be so accurately linear as they actually are. But this point can only be settled by experiment, and it seems to us that it is well worth while to give the perhaps too hastily discarded water surface a further trial.

This is all the more desirable, since the only other alternative-that of standardization by comparison with a standard atmometer-is at best a pis aller. The impossibility of standardizing one's instrument oneself is an inconvenience, and the fact that the standard alters as time goes on points to the possibility of the introduction of errors which, small in themselves, may in time accumulate to something very serious.

There are several other points of interest to the physiologist which are, perhaps, outside the scope of this paper ; in particular, the evaporation from small apertures in currents of air of various velocities demands accurate experimental investigation. We have seen that, ceteris paribus, the change from a quiet room to a slightly disturbed atmosphere produces a small but definite alteration in the value of $n$, and this change is primarily due to the distortion of the lines of flow of the vapour in the neighbourhood of the evaporating surface caused by the motion of the air. If, therefore, quantitative experiments be made on the evaporation from small apertures in streams of air moving with various velocities, the variation in the values

1 Livingston: A Rotating Table for standardizing Porous-cup Atmometers. Plant World, I5, 1912.

2 Ibid. : Atmometry and the Atmometer. Plant World, I8, I9I5. 
obtained for $n$ should give important information as to the magnitude of the air film which is at rest in contact with the surface. Such information could probably be usefully applied to the analogous case of a transpiring leaf surface exposed to a breeze. We hope in the future to communicate the results of experiments dealing with this point.

The greater part of the above work was done in the Physics Department of the University College of North Wales, Bangor, in the summer of I9I6, and we desire here to express our appreciation of the assistance given to us by Professor E. Taylor Jones in generously placing at our disposal the resources of his department. Our thanks are also due to Professor V. H. Blackman, who has criticized our manuscript and to whose knowledge of the literature of the subject we owe several of our references.

\section{Summary.}

Experiments are described which show that the evaporation from a circular water surface is not, as commonly assumed, proportional to its area, unless the depth of the surface below the rim of the containing vessel be greater than two or three centimetres; nor is it proportional to the linear dimensions of the basin, but for basins 'full' of water it is approximately proportional to (radius) $\frac{3}{2}$.

Serious errors-sometimes of the magnitude of 40 per cent.-may therefore arise in determining the water surface equivalent to a given atmometer, and methods of calibration are described by which such errors may be avoided.

The figures usually given to show the relation between the evaporation from a transpiring leaf surface and a circular water surface of the same area are also subject to serious errors, and, simple as the experiment is, stand in need of re-determination. 


\section{$2 \mathrm{BHL}$ Biodiversity Heritage Library}

Thomas, Nesta and Ferguson, Allan. 1917. "On the reduction of transpiration observations." Annals of botany 31, 241-255.

https://doi.org/10.1093/oxfordjournals.aob.a089643.

View This Item Online: https://www.biodiversitylibrary.org/item/232813

DOI: https://doi.org/10.1093/oxfordjournals.aob.a089643

Permalink: https://www.biodiversitylibrary.org/partpdf/320186

\section{Holding Institution}

Smithsonian Libraries

\section{Sponsored by}

Biodiversity Heritage Library

\section{Copyright \& Reuse}

Copyright Status: Not in copyright. The BHL knows of no copyright restrictions on this item.

This document was created from content at the Biodiversity Heritage Library, the world's largest open access digital library for biodiversity literature and archives. Visit BHL at https://www.biodiversitylibrary.org. 